\title{
Cíxidos y dérbidos (Hemiptera) vectores putativos de fitoplasma del grupo 16Sr-IV
}

\author{
Cixiidae and Derbidae (Hemiptera) putative vectors of phytoplasma of group $16 \mathrm{SrIV}$
}

\author{
EDER RAMOS-HERNÁNDEZ ${ }^{1}$; JULIA MARÍA LESHER-GORDILLO²; \\ CARLOS FREDY ORTIZ-GARCÍA ${ }^{3}$; CARLOS OROPEZA-SALÍN ${ }^{4}$; \\ SAÚL SÁNCHEZ-SOTO ${ }^{5}$; MIGUEL A. MAGAÑA-ALEJANDRO; \\ MARÍA DEL S. NARVÁEZ-CAB ${ }^{7}$
}

\begin{abstract}
${ }^{1} \mathrm{Ph}$. D. Ecología y Manejo de Sistemas Tropicales, Instituto Nacional de Investigaciones Forestales, Agrícolas y Pecuarias, Campo experimental Huimanguillo, Huimanguillo, Tabasco, México, eder1978@hotmail.com, https://orcid.org/0000-0001-6860-4212. ${ }^{2}$ Ph. D. Ciencias y Tecnología de Alimentos, División Académica de Ciencias Biológicas, Universidad Juárez Autónoma de Tabasco, Villahermosa, Tabasco, México,julialesher1@gmail.com, https:// orcid.org/0000-0001-6973-2304. ${ }^{3}$ Ph. D. Ciencias en Biología Molecular, Colegio de Postgraduados, Campus Tabasco, H. Cárdenas, Tabasco, México, cfortiz@colpos.mx, https://orcid.org/0000-0002-6820-9252. ${ }^{4} \mathrm{Ph}$. D. Bioquímica Vegetal, Centro de Investigación Científica de Yucatán, Mérida, Yucatán, México, cos@cicy.mx, https://orcid.org/0000-0002-7352-3692. ${ }^{5} \mathrm{Ph}$. D. Entomología, Colegio de Postgraduados, Campus Tabasco, H. Cárdenas, Tabasco, México, sssoto@colpos.mx, https://orcid.org/0000-0001-5080-4611. ${ }^{6} \mathrm{Ph}$. D. Ecología y Manejo de Sistemas Tropicales, División Académica de Ciencias Biológicas, Universidad Juárez Autónoma de Tabasco, Villahermosa, Tabasco, México, manglarujat@hotmail.com, https://orcid.org/0000-0001-5024-1580. ${ }^{7} \mathrm{Ph}$. D. Ciencias de los Alimentos y Biotecnología, Centro de Investigación Científica de Yucatán, Mérida, Yucatán, México, maryn@cicy.mx, https://orcid. org/0000-0002-9537-4923.
\end{abstract}

Autor para correspondencia

Carlos Fredy Ortiz-García. Ph. D. Ciencias en Biología Molecular. Colegio de Postgraduados. C. P. 86500, Campus Tabasco, Periférico Carlos a Molina, km $3.5 \mathrm{~s} / \mathrm{n}$, Carretera Cárdenas Huimanguillo, H. Cárdenas, Tabasco México, cfortiz@colpos.mx,https://orcid.org/0000-00026820-9252

\section{Citación sugerida}

RAMOS-HERNÁNDEZ, E.; LESHERGORDILLO, J. M.; ORTIZ-GARCÍA, C. F.; OROPEZA-SALÍN, C.; SÁNCHEZSOTO, S.; MAGAÑA-ALEJANDRO, M. A.; NARVẢEZ-CAB, M. del S. 2020. Cíxidos y dérbidos (Hemiptera) vectores putativos de fitoplasma del grupo 16Sr-IV. Revista Colombiana de Entomología 46 (2): e7065. https://doi.org/10.25100/socolen.v46i2.7065

Recibido: 28-sep-2018

Aceptado: 12-may-2020

Publicado: 31-dic-2020

Revista Colombiana de Entomología ISSN (Print): 0120-0488

ISSN (On Line): 2665-4385

https://revistacolombianaentomologia.univalle.edu.co

Open access

(c) (i) (2) (2) BY-NC-SA 4.0

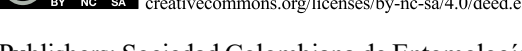
SOCOLEN (Bogotá, D. C., Colombia) https://www.socolen.org.co

Universidad del Valle (Cali, Colombia)

https://www.univalle.edu.co

(C) 2020 Sociedad Colombiana de Entomología - SOCOLEN y Universidad del Valle - Univalle
Resumen: Los fitoplasmas del grupo 16SrIV causan enfermedades tipo amarillamiento letal (STAL) en palmas a nivel mundial. El fitoplasma del amarillamiento letal del cocotero (ALC) se conoce como 'Candidatus Phytoplasma palmae' (16SrIV-A). Al igual que en el ALC, muchas enfermedades causadas por fitoplasma a nivel mundial, sus vectores no han sido identificados. El único vector del fitoplasma del ALC incriminado es Haplaxius crudus (Hemiptera: Cixiidae). El objetivo del presente estudio fue determinar la presencia del fitoplasma 16SrIV en cíxiidos y dérbidos asociados a palmas (Adonidia merrillii y Cocos nucifera) positivas a fitoplasmas. Se realizaron capturas de insectos asociados a estas palmas durante la mañana y tarde. La presencia de fitoplasma fue determinada por PCR en tiempo real, empleando los cebadores TaqMan LY16S-ANYF (GCTAAGTCCCCACCATAACGT) y LY16S-ANYR (CGTGTCGTGAGAT-GTTAGGTTAAGT); sonda LY16S-ANYM (FAMCCCCTGTCGTTAATTG-NFQ). No se detectó la presencia de fitoplasma del grupo $16 \mathrm{SrIV}$ en $H$. crudus aunque sí se mostró su presencia en $H$. skarphion (Hemiptera: Cixiidae), Oecleus snowi (Hemiptera: Cixiidae) y Persis foveatis (Hemiptera: Derbidae). Estos resultados sugieren que estas tres especies pueden ser potenciales vectores del fitoplasma del grupo 16 SrIV en palmas.

Palabras clave: Palmas, PCR tiempo real, vector de fitoplasma, Haplaxius crudus, Haplaxius skarphion, Oecleus snowi, Persis foveatis, Cixiidae, Derbidae, Hemiptera.

\begin{abstract}
The phytoplasmas of the 16SrIV group cause lethal yellowing diseases (STAL) in palms worldwide. The Phytoplasma of coconut lethal yellowing (LY) has been known as 'Candidatus Phytoplasma palmae' (16SrIV-A). Like LY, many diseases caused by phytoplasma worldwide, their vectors have not been identified. The only incriminated phytoplasma vector of the LY is Haplaxius crudus (Hemiptera: Cixiidae). The objective of the present study was to determine the presence of $16 \mathrm{SrIV}$ phytoplasma in cixiids and derbids associated with palms (Adonidia merrillii y Cocos nucifera) positive to phytoplasmas. Captures of insects associated with these palms were made during the morning and afternoon. The presence of phytoplasma was determined by the real-time PCR using the TaqMan LY16S-ANYF (GCTAAGTCCCCACCATAACGT) and LY16S-ANYR (CGTGTCGTGAGAT-GTTAGGTTAAGT) primers; probe LY16S-ANYM (FAMCCCCTGTCGTTAATTG-NFQ). The presence of phytoplasma of the 16SrIV group was not detected in $H$. crudus although its presence was shown in H. skarphion (Hemiptera: Cixiidae), Oecleus snowi (Hemiptera: Cixiidae) and Persis foveatis (Hemiptera: Derbidae). These results suggest that these three species may be potential vectors of phytoplasma of group $16 \mathrm{SrIV}$ in palms.
\end{abstract}

Keywords: Palms, PCR real time, phytoplasma vector, Haplaxius crudus, Haplaxius skarphion, Oecleus snowi, Persis foveatis, Cixiidae, Derbidae, Hemiptera. 


\section{Introducción}

Los fitoplasmas son patógenos de plantas que pertenecen al grupo de las bacterias gram-positivas. Estos patógenos habitan en los tubos cribosos del floema de las plantas y en diferentes órganos de su insecto vector (Bertaccini et al. 2014). En la naturaleza los fitoplasmas son transmitidos por insectos vectores en una manera propagativa y persistente, frecuentemente, permaneciendo infectivos durante toda su vida (Weintraub y Beanland 2006; Bosco y Tedeschi 2013). Como los fitoplasmas están limitados al floema, su transmisión entre plantas es por insectos del orden Hemiptera que se alimentan del floema, principalmente, Cicadoidea, Fulgoroidea y Psylloidea (Weintraub y Beanland 2006).

La transmisión del fitoplasma depende del número de plantas que este puede infectar, como también de la población del vector y su hábito alimenticio: monófaga, oligófaga y polífaga (Lee et al. 2000). La transmisión se basa en tres etapas fundamentales: adquisición, latencia e inoculación (Bosco y Tedeschi 2013). Durante la adquisición, el insecto ingiere el fitoplasma al alimentarse sobre una planta infectada (Dickinson et al. 2013). El periodo de latencia, o de incubación, es el intervalo de tiempo entre adquisición y el inicio de infectividad (Bosco et al. 2009). Durante esta fase, el fitoplasma invade el cuerpo del insecto vía hemolinfa, se multiplica y llega a las glándulas salivares (Bosco y Tedeschi 2013; Rashidi et al. 2014). Una vez se completa el periodo de latencia, el insecto puede inyectar los fitoplasmas directamente en los tubos cribosos de plantas sanas (Hogenhout et al. 2008). Por lo tanto, los vectores putativos pueden ser aislados, individualmente $\mathrm{o}$ en lotes, con plantas sanas para evaluar la capacidad de transmisión del fitoplasma.

Los fitoplasmas del grupo $16 \mathrm{SrIV}$ causan enfermedades con síntomas tipo amarillamiento letal (STAL) en palmas de diferentes zonas geográficas (Mpunami et al. 2001). En la actualidad, este grupo se ha dividido en seis subgrupos, 16SrIV-A (Vázquez-Euán et al. 2011), 16SrIV-B (Tymon et al. 1998), 16SrIV-C (Tymon et al. 1997), 16SrIV-D (Córdova et al. 2000; Harrison et al. 2002), 16SrIV-E (Martínez et al. 2008) y 16 SrIV-F (Harrison et al. 2008). El grupo 16SrIV-A, incluye al fitoplasma del amarillamiento letal del cocotero (ALC), que ha causado grandes devastaciones de áreas cocoteras de Jamaica, Florida (EE. UU) y México (Myrie et al. 2007; Harrison et al. 2008; Vázquez-Euán et al. 2011). Sin embargo, estos subgrupos de STAL, pueden diferir en su epidemiología, la susceptibilidad de los cultivares de coco y los insectos vectores (Mpunami et al. 2001).

El ritmo de identificación de fitoplasma no ha ido a la par con la identificación de sus correspondientes vectores (Weintraub 2007). Al igual que para muchas enfermedades causadas por fitoplasma, en otros cultivos a nivel mundial, en cocotero el Haplaxius crudus Van Duzee, 1907 (Hemiptera: Cixiidae), es el único vector del ALC identificado a la fecha (Howard 1986) y potencialmente, dérbidos del género Cedusa spp. en Jamaica (Brown et al. 2006). En Estados Unidos se sospecha que el Flatidae Ormenaria rufifascia (Walker, 1851), y el Derbidae, Omolicna joi Wilson, Halbert \& Bextine, 2014, pueden ser vectores del fitoplasma 16SrIV-D que causan la enfermedad del bronceado letal [LBD] (Powell et al. 2015).

Labúsqueda de insectos vectores de fitoplasmas causantes de enfermedades con STAL en palmas ha sido infructuosa (Dollet et al. 2011), crítica y, por consiguiente, aún se dificulta su control. En las investigaciones recientes sobre vectores putativos del ALC solo se han usado herramientas moleculares para determinar la presencia de fitoplasma en los insectos en estudio. Mpunami et al. (2001) asociaron la transmisión de la enfermedad letal (LD) en Tanzania con el Derbidae Diostrombus mkurangai (Wilson, 1987) y a Meenoplus sp. (Hemiptera: Meenoplidae). Curiosamente, D. mkurangai ha sido reportado como potencial vector del fitoplasma ' $\mathrm{Ca}$. Phytoplasma palmicola' en Mozambique (Bila et al. 2017) y de la enfermedad de Kerala Wilt en la India (Edwin y Mohankumar 2007), por lo que esta especie pudiera albergar más de un grupo de fitoplasma relacionado. En la provincia de Cabo Delgado, norte de Mozambique, se descubrió que algunos Pentatomidae de las especies Platacantha lutea (Westwood, 1844) portaban el mismo fitoplasma identificado en cocotero enfermo (Dollet et al. 2011). Con este mismo enfoque, Cicadellidae de la especie Nedotepa curta Dmitriev, 2016 y el Derbidae, Proutista fritillaris (Boheman, 1838) fueron encontrados positivos al fitoplasma causante del amarillamiento letal de Costa de Marfil (CILY) (Kwadjo et al. 2018). Cabe señalar, que la detección positiva a fitoplasma en un insecto, no demuestra su capacidad como vector del patógeno; sin embargo, estas detecciones pueden ayudar para que los investigadores realicen experimentos de transmisión con vectores putativos (Bila et al. 2017). Hasta este estudio se desconocía la identidad de insectos portadores de fitoplasma del ALC en las áreas de Tabasco, México. Sin embargo, las poblaciones de H. skarphion Kramer, 1979 (Hemiptera: Cixiidae), Oecleus snowi Ball, 1905 (Hemiptera: Cixiidae) y Persis foveatis Caldwell, 1944 (Hemiptera: Derbidae) eran abundantes en las palmas con sintomatología del ALC. Por lo cual, se exploraron estas especies en búsqueda de posibles vectores del fitoplasma del grupo $16 \mathrm{SrIV}$.

La identificación del agente causal del ALC se realiza mediante la técnica reacción en cadena de la polimerasa (PCR) en regiones variables dentro del gen 16S rARN (Davis y Lee 1993) o 16 - 23Sr (Smart et al. 1996). Esto permite la detección y caracterización molecular de fitoplasmas en palmas e insectos. La mayoría de los ensayos con PCR convencional implican un procedimiento de PCR anidada para mejorar la sensibilidad. Sin embargo, la PCR en tiempo real ha demostrado alta especificidad y amplio rango de detección (Christensen et al. 2013), además, es mucho menos sensible a la contaminación ya que no requiere ningún procesamiento post-PCR (Jarausch et al. 2010). La detección de PCR en tiempo real combina la amplificación y la detección en un mismo paso, al correlacionar el producto de la PCR de cada uno de los ciclos con una señal de intensidad de fluorescencia (Christensen et al. 2013). Esta técnica se ha utilizado principalmente para cuantificar la concentración de fitoplasma en las plantas (Brown et al. 2007). Considerando las ventajas descritas sobre PCR en tiempo real, se planteó el objetivo de identificar insectos con presencia de fitoplasma del grupo 16SrIV. Estos resultados buscan ampliar el conocimiento sobre especies de insectos hospederos de fitoplasma asociados a palmas con STAL. Además, esta detección sirve para reducir el número de especies que podrían ser convenientemente seleccionadas para realizar ensayos de transmisión, aumentando la probabilidad de identificar el vector de la enfermedad (Liu et al. 2017).

\section{Materiales y métodos}

Recolecta de insectos. Los cíxiidos y dérbidos se recolectaron sobre las de palmas Adonidia merrillii (Becc.) Becc. y Cocos nucifera L. La presencia de fitoplasma del grupo 
16SrIV en estas dos especies de palmas fue confirmada por PCR en tiempo real.

Las capturas de insectos se llevaron a cabo en los municipios de Cárdenas y de Cunduacán, Tabasco, México. La recolecta se realizó en dos periodos del día: 07:00 - 09:00 hs y 18:00 - 20:00 hs. Los insectos se capturaron del foliolo de las palmas usando la trampa manual descrita por Narváez et al. (2018). El uso de este sistema ayuda a capturar insectos minimizando el estrés y los daños mecánicos que pudieran sufrir durante la manipulación. Los insectos se almacenaron en etanol al $90 \%$ a $-20{ }^{\circ} \mathrm{C}$ hasta su posterior identificación y extracción de ADN.

Identificación de insectos. En el laboratorio, los especímenes fueron separados en morfo especies y, posteriormente, al microscopio-estereoscopio se hizo su identificación a nivel de especie de acuerdo con las claves de Kramer (1979); Sforza et al. (1999); Bartlett et al. (2014) y Wilson (2005). Algunos dérbidos solo se identificaron a nivel de género.

Análisis molecular. El ADN total de cada insecto se extrajo utilizando el método descrito por Harrison et al. (1996) y Brown et al. (2006). Se eliminó el etanol de los insectos antes de iniciar el procedimiento de extracción. Los insectos fueron colocados individualmente en microtubos de $1,5 \mathrm{ml}$ con $300 \mu \mathrm{l}$ de buffer de extracción CTAB [2 \% CTAB; $100 \mathrm{mM}$ Tris-HCl, pH 8,0; 20 mM EDTA, pH. 8,0; 3M NaCl; 1 \% PVP-40 y 1 $\%$ 2-mercaptoetanol] y fueron macerados con micro pistilos. Las muestras maceradas se incubaron por 1 hora a $65^{\circ} \mathrm{C}$, se enfriaron a temperatura ambiente y se les agregó $300 \mu \mathrm{L}$ de fenol-cloroformo-alcohol isoamílico (25:24:1). Las mezclas se emulsionaron con vortex a alta velocidad y luego se centrifugaron a $14.000 \mathrm{rpm}$ por 10 minutos para separar las fases, $\mathrm{y}$ los ácidos nucleicos se precipitaron de la fase acuosa con acetato de sodio $3 \mathrm{M}$ y volúmenes de isopropanol frío $(30 \mu \mathrm{l}$ y $180 \mu \mathrm{l}$, respectivamente) a $-20^{\circ} \mathrm{C}$ por $1 \mathrm{~h}$. Los ácidos nucleicos se sedimentaron por centrifugación por 10 minutos a $14.000 \mathrm{rpm}$. Las pastillas de ADN se lavaron con $100 \mu \mathrm{L}$ de etanol al $70 \%$, se secaron a temperatura ambiente y re-suspendidas en $30 \mu \mathrm{lde}$ buffer TE (10 mM Tris, 1 mM EDTA, pH. 8). El ADN total obtenido de los insectos se visualizó por electroforesis en geles de agarosa al $1 \%$ en buffer TAE $1 \mathrm{X}$ teñido con bromuro de etidio.

PCR en tiempo real. El ADN total extraído de cada insecto fue diluido en 1:10 con agua desionizada estéril, y de esta dilución se utilizó $2 \mu 1$ como molde para cada mezcla de reacción de PCR tiempo real. La mezcla de reacción para las amplificaciones por PCR en tiempo real fue realizada de acuerdo con Córdova et al. (2014). Las reacciones fueron realizadas en volúmenes de $20 \mu$ l. Cada reacción contenía $10 \mu \mathrm{l}$ de TaqMan Universal PCR con AmpErase UNG (uracil N-gluccolasa) (Applied Biosystems, EE. UU.), $1 \mu \mathrm{l}$ de mezcla de cebador que contiene $900 \mathrm{nM}$ de cada cebador, $2 \mu 1$ sonda $(250 \mathrm{nM}), 2$ $\mu 1$ de muestra del molde de ADN y $5 \mu l$ de agua grado biología molecular (Invitrogen, Carlsbad, EE. UU.). Para la detección de fitoplasma asociado al amarillamiento letal de cocotero, subgrupos 16SrIV-A, D y E, se utilizó el par de cebadores TaqMan LY16S-LSF (5'- GCTAAAGTCCCCACCATAACGT-3') y LY16S-LSR (5'-CGTGTCGTGAGATGTTAGGTTAAGT-3') y la sonda (FAM-CCCCTGTCGTTAATTG-NFQ) (Córdova et al. 2014). La amplificación fue realizada utilizando un termociclador Rotor-Gene ${ }^{\circledR}$ Q (Qiagen, EE. UU.). La PCR fue realizada en dos etapas: un ciclo previo a la reacción a $50{ }^{\circ} \mathrm{C}$ por dos minutos y otro ciclo a $95{ }^{\circ} \mathrm{C}$ por 10 minutos para activar la polimerasa AmpliTaq Gold, seguido de 40 ciclos de amplificación a $95^{\circ} \mathrm{C}$ durante 15 segundos y 1 minuto a $61^{\circ} \mathrm{C}$. Después se cuantificó el producto de la reacción. Los valores de ciclo umbral $(\mathrm{Ct})$ de cada reacción de PCR se establecieron manualmente para intersectar la fase exponencial de las curvas de amplificación, pero las líneas de base se establecieron automáticamente por Rotor-Gene Q Series Software 2.0.2 (QIAGEN, EE. UU.). El control negativo utilizado fue ADN extraído de plantas asintomáticas y agua estéril. El control positivo fue ADN de palma (Acc. No. GU473590) e identificada como 16SrIV-A (Vázquez-Euán et al. 2011).

\section{Resultados y discusión}

Se recolectaron 66 individuos de Cixiidae y 29 de Derbidae sobre palmas de cocotero y A. merrillii con ALC. En la Tabla 1 se presenta el número de individuos identificados por familia y especie. Del total de insectos capturados y analizados con la técnica de PCR tiempo real, usando la sonda TaqMan y los cebadores específicos para fitoplasma del grupo de amarillamiento letal (16SrIV), 11 Haplaxius, seis Oecleus y siete Persis fueron positivos para este patógeno. La PCR en tiempo real utilizado en este estudio demuestra que tiene la capacidad de detectar insectos positivos al fitoplasma del ALC como lo mencionan Myrie et al. (2011).

Dado que, en este estudio, del total de insectos positivos, el $100 \%$ fue capturado durante la mañana (Tabla 1), lo cual, sugiere una mayor oportunidad de realizar recolectas de insectos positivos durante este periodo, con la finalidad de realizar ensayos de transmisión. En reciente ensayo de transmisión se ha demostrado que $H$. crudus puede trasmitir fitoplasma 16SrIV -A y -D a palmas de Pritchardia pacifica Seem. \& H. Wendl. (CICY, resultados no publicados).

Detección de fitoplasma 16SrIV en muestras de insectos. El cíxiido, $H$. crudus es el único vector confirmado del ALC en el continente americano (Howard et al. 1983) y tiene importancia económica por su papel como vector de este patógeno y su asociación al cocotero en la etapa adulta (Tsai et al. 1976; Howard 1986). En el presente estudio, durante febrero y marzo del 2015, se capturaron 19 individuos de esta especie en el municipio de Cárdenas. Ningún individuo fue positivo a fitoplasma del grupo 16SrIV con PCR en tiempo real (Tabla 1), a pesar de que $A$. merrillii, palma en la cual se realizaron las capturas

Tabla 1. Detección de fitoplasma del grupo 16 SrIV por PCR en tiempo real en cíxiidos y dérbidos (Hemiptera). Individuos recolectados en Cárdenas y Cunduacán, Tabasco, México.

\begin{tabular}{|c|c|c|c|c|c|}
\hline \multirow{2}{*}{ Especies } & \multicolumn{2}{|c|}{ Mañana } & \multicolumn{2}{|c|}{ Tarde } & \multirow{2}{*}{ Total de insectos } \\
\hline & Pos. & Neg. & Pos. & Neg. & \\
\hline \multicolumn{6}{|c|}{ Cixiidae } \\
\hline Haplaxius crudus & 0 & 5 & 0 & 14 & $19 K$ \\
\hline Haplaxius skarphion & 11 & 16 & 0 & 8 & $35 K, C$ \\
\hline Oecleus snowi & 6 & 6 & - & - & $12 C$ \\
\hline \multicolumn{6}{|c|}{ Derbidae } \\
\hline Persis foveatis & 7 & 14 & - & - & $21 C$ \\
\hline Otros Derbidae & 0 & 8 & - & - & $8 C$ \\
\hline Total & 24 & 49 & 0 & 22 & 95 \\
\hline
\end{tabular}

Palma de captura: $K=$ Adonidia merrilli; $C$ : Cocos nucifera. Pos.= positivos; Neg.= negativos. 
por la mañana y noche, fue positiva a ese fitoplasma. Haplaxius crudus se alimenta de forma restringida del floema ubicado en las hojas de palmas o en su totalidad de plantas monocotiledóneas (Howard 1986). También puede permanecer inmóvil durante largos periodos en la superficie del envés de las hojas, próximas al nervio central o utilizar como refugio el punto donde los foliolos se unen al raquis (Howard 2001). Tsai y Kirsch (1978), observaron durante cinco meses que el 65,25\% de los individuos de $H$. crudus es atraído a las palmas de cocotero durante las horas de tarde. Los adultos emigran a palmas en la noche y durante las mañanas muchos regresan al pasto cuando las temperaturas comienzan a incrementar después de la salida del sol (Reinert 1977). Sin embargo, ciertas especies de palmas y variedades son más atractivas que otras a los adultos de $H$. crudus (Howard 1986).

El número de individuos de $H$. crudus capturados sobre las hojas de $A$. merrilli en el presente trabajo puede ser considerado bajo. En contraste, Reinert (1977) menciona que se pueden encontrar hasta 50 individuos adultos de este cíxiido/ hoja de cocotero. Sin embargo, algunos autores reportan bajo porcentaje de insectos positivos a pesar de capturar y analizar un gran número de individuos de esta especie. Así, VázquezEuán (2010), analizó un total de 1,809 individuos de H. crudus capturados en cuatro sitios distintos del estado de Yucatán durante 2007 - 2008, de ellos 23 casos fueron positivos, es decir, 1,3\% del total de insectos donde la presencia de plantas positivas al ALC había sido confirmada. Además, después de analizar alrededor de 800 individuos de H. crudus capturados en sitios afectados por ALC, la detección positiva fue obtenida en el $4 \%$ de los insectos probados. Este porcentaje tan bajo de positivos podría estar estrechamente relacionado al poco éxito que han tenido los ensayos de transmisión en otras regiones de América, sin lograr la transmisión, como en Jamaica (Brown et al. 2006; Eden-Green 1979) y México (Dzido 2010 , com. pers.). También se han utilizado plantas de cocotero en edad no reproductiva y especies de palmas más pequeñas para realizar ensayos de transmisión (Thomas y Norris 1980); sin embargo, no se ha logrado la transmisión con $H$. crudus en varias regiones del Caribe fuera de la Florida. Así mismo, en África se han repetido ensayos de transmisión para identificar el vector del Cape Saint Paul Wilt (CSPWD) en Ghana, siendo el principal sospechoso Myndus adiopoduemeensis Synave (Homoptera: Cixiidae) (Dery et al. 1996).

En este estudio, de 35 individuos del congénere $H$. skarphion, 11 fueron positivos al fitoplasma del grupo $16 \mathrm{SrIV}$ (Tabla 1), lo que se considera alto, si se compara con las detecciones de fitoplasmas realizadas en plantaciones de cocotero en otros países. Dollet et al. (2010) en la provincia de Granma, Cuba, registraron otro cíxiido, Nymphocixia caribbea (Fennah) abundante en una plantación donde había ALC y encontraron 15/91 individuos positivos al fitoplasma del ALC. Por el contrario, Mpunami et al. (2001) en las búsquedas de vectores de enfermedad letal del cocotero en Tanzania reportaron un número bajo de insectos positivos al fitoplasma, 8/1270 de la especie Diastrombus mkurangai Wilson (Homoptera: Derbidae) y 4/14 de Meenoplus spp. (Meenoplidae).

Otra especie de la familia Cixiidae asociada a $C$. nucifera y $A$. merrilli positivas a fitoplasma del grupo $16 \mathrm{SrIV}$ fue $O$. snowi. Al efectuar el diagnóstico molecular por PCR en tiempo real para la detección del fitoplasma (Tabla 1), se obtuvo que seis individuos resultaron positivos al 16SrIV. La distribución de $O$. snowi fue revisada por Kramer (1977), aunque sólo para el norte de México. Aunque gran parte de la fauna de Oecleus mesoamericana aún no se ha estudiado sistemáticamente, esta especie es particularmente importante como potencial vector de fitoplasmas del 16SrIV (Bartlett et al. 2018). Estos resultados resaltan la importancia que puede tener esta especie como vector putativo de fitoplasmas en las plantaciones de cocotero.

El análisis de insectos de otras familias como vectores putativos del fitoplasma del grupo del ALC aportó resultados favorables (Tabla 1). De 21 individuos de $P$. foveatis, siete adultos capturados en plantas de cocotero de las comunidades de Miahuatlán 2da secc., Cunduacán y Habanero 2da. Secc., Cárdenas, fueron positivos al fitoplasma 16SrIV. Otras especies de dérbidos de los géneros Cedusa y Otiocerus, que se capturaron en palmas de cocotero de Pailebot y R/a Habanero del municipio de Cárdenas. Dos de tres individuos de Cedusa, resultaron positivos al fitoplasma del grupo de ALC mientras que los especímenes de Otiocerus fueron negativos. En Jamaica, Brown et al. (2006), reportan que de 13 Derbidae que portaban el fitoplasma del grupo del ALC, seis tenían una cepa diferente de fitoplasma del grupo ALC. Esto indica que para el género Cedusa los fitoplasmas podrían pertenecer a diferentes subgrupos que integran al grupo 16SrIV.

En este estudio, la detección positiva de $H$. skarphion, $O$. snowi y $P$. foveatis nos lleva a considerar que es probable que exista un vector del ALC distinto a H. crudus, en Tabasco. Sin embargo, algunas investigaciones reportan que los insectos recolectados en campo y con la presencia fitoplasmas, han sido incapaces de transmitir el patógeno en cautiverio (Galetto et al. 2019). Es importante anotar que para que el fitoplasma sea transmitido, debe ingresar a células específicas de las glándulas salivares y pasar a la hemolinfa. En caso contrario el insecto se clasifica como hospedero "sin salida" (Brown et al. 2006), por lo tanto, la penetración y reproducción del fitoplasma en las glándulas salivales son requisitos previos para su transmisión (Hogenhout et al. 2008). El periodo de latencia es el tiempo entre el momento en que el insecto adquiere el fitoplasma y el desarrollo de una concentración infecciosa en las glándulas salivales. Así, los fitoplasmas pueden ser detectados en el interior de los insectos después de alimentarse de plantas enfermas (Dollet et al. 2010), sin ser capaces de transmitir el patógeno (Lu et al. 2016). En consecuencia, varias especies de insectos son capaces de adquirir, pero no de transmitir los fitoplasmas (Galetto et al. 2019). Bressan et al. (2006), consideran que probablemente los insectos pueden albergar células de fitoplasmas en sus cuerpos, pero la capacidad para transmitir fitoplasma depende de la combinación patógeno-planta hospedera-insecto vector, y varios factores, como un mecanismo molecular especifico de reconocimiento del hospedero. El ADN del fitoplasma puede ser detectado en el intestino del insecto o después de alimentarse de plantas infectadas sin que sea capaz de transmitir el patógeno (Lu et al. 2016). Aunque la detección del fitoplasma en un insecto no necesariamente provee el estatus como vector (Liu et al. 2017), sí, es un paso hacia su identificación como tal. Por lo que realizar ensayos de transmisión con estas especies sería recomendable para su rol putativos de vectores del ALC.

\section{Conclusiones}

Los resultados de este estudio sugieren a las especies $H$. skarphion, O. snowi y $P$. foveatis como vectores putativos del fitoplasma del grupo 16SrIV. No obstante, no se determinó a cuál subgrupo de fitoplasma dentro del grupo $16 \mathrm{SrIV}$, portaban los insectos positivos. 


\section{Agradecimientos}

A la Comunidad Europea (CE), por el financiamiento del proyecto "Enfermedades asociadas a procariotas transmitidas por insectos en cultivos perennes tropicales y subtropicales" (TROPICSAFE: Acuerdo de subvención no: 727459).

\section{Literatura citada}

BARTLETT, C. R.; O'BRIEN, L. B.; WILSON, S. W. 2014. A review of the planthoppers (Hemiptera: Fulgoroidea) of the United States. Memoirs of the American Entomological Society 50: 1-298. https://ia801201.us.archive.org/28/items/memoirsofamerica 5020amer/memoirsofamerica5020amer.pdf

BARTLETT, C. R.; PASSOS, E. M.; SILVA, F. G.; DINIZ, L. E. C.; DOLLET, M. 2018. A new species of Oecleus Stål (Hemiptera: Fulgoroidea: Cixiidae) from coconut in Brazil. Zootaxa 4472 (2): 358-364. https://doi.org/10.11646/zootaxa.4472.2.8

BERTACCINI, A.; DUDUK, B.; PALTRINIERI, S.; CONTALDO, N. 2014. Phytoplasmas and phytoplasma diseases: a severe threat to agriculture. American Journal of Plant Sciences 5 (12): 1763-1788. https://doi.org/10.4236/ajps.2014.512191

BILA, J.; MONDJANA, A.; SAMILS, B.; HÖGBERG, N.; WILSON, M. R.; SANTOS, L. 2017. First report of 'Candidatus Phytoplasma palmicola' detection in the planthopper Diostrombus mkurangai in Mozambique. Bulletin of Insectology 70 (1): 45-48. http://www.bulletinofinsectology.org/pdfarticles/vol702017-045-048bila.pdf

BOSCO, D.; TEDESCHI, R. 2013. Insect vector transmission assays. En: Dickinson, M.; Hodgetts, J. (Eds.). Phytoplasma. Methods in molecular biology (Methods and Protocols). Vol. 938. Humana Press, Totowa, NJ. 421 p. https://doi.org/10.1007/978-1-62703089-2 7

BOSCO, D.; D'AMELIO, R.; WEINTRAUB, P. G.; JONES, P. 2009. Transmission specificity and competition of multiple phytoplasmas in the insect vector. pp. 293-308. En: Weintraub, P. G.; Jones, P. (Eds.). Phytoplasmas: genomes, plant hosts and vectors. CABI. Wallingford, Reino Unido. 352 p. https://doi. org/10.1079/9781845935306.0293

BRESSAN, A.; CLAIR, D.; SÉMÉTEY, O.; BOUDON-PADIEU, E. 2006. Insect injection and artificial feeding bioassays to test the vector specificity of Flavescence dorée phytoplasma. Phytopathology 96 (7): 790-796. https://doi.org/10.1094/ PHYTO-96-0790

BROWN, S. E.; BEEN, B. O.; McLAUGHLIN, W. A. 2006. Detection and variability of the lethal yellowing group (16Sr IV) phytoplasmas in the Cedusa sp. (Hemiptera: Auchenorrhyncha: Derbidae) in Jamaica. Annals of Applied Biology 149 (1): 53-62. https://doi.org/10.1111/j.1744-7348.2006.00072.x

BROWN, S. E.; BEEN, B. O.; McLAUGHLIN, W. A. 2007. The lethal yellowing (16SrIV) group of phytoplasmas. Pest Technology 1 (1): 61-69. http://www.globalsciencebooks.info/Online/ GSBOnline/images/0706/PT_1(1)/PT_1(1)61-69o.pdf

CHRISTENSEN, N. M.; NYSKJOLD, H.; NICOLAISEN, M. 2013. Real-time PCR for universal phytoplasma detection and quantification. pp. 245-252. En: Dickinson M.; Hodgetts, J. (Eds.). Phytoplasma. Methods in molecular biology (Methods and Protocols). Vol. 938. Humana Press, Totowa, NJ. 421 p. https://doi. org/10.1007/978-1-62703-089-2 21

CÓRDOVA, I.; OROPEZA, C.; ALMEYDA, H.; HARRISON, N. A. 2000. First report of a phytoplasma-associated leaf yellowing syndrome of Palma Jipi plants in Southern Mexico. Plant Disease 84 (7): 807-807. https://doi.org/10.1094/PDIS.2000.84.7.807A

CÓRDOVA, I.; OROPEZA, C.; PUCH-HAU, C.; HARRISON, N.; COLLÍ-RODRÍGUEZ, A.; NARVÁEZ, M.; NIC-MATOS, G.; REYES, C.; SÁENZ, L. 2014. A real-time PCR assay for detection of coconut lethal yellowing phytoplasmas of group 16 SrIV subgroups A, D and E found in the Americas. Journal of Plant Pathology 96 (2): 343-352. http://doi.org/10.4454/JPP. V96I2.031

DAVIS, R. E.; LEE, I. M. 1993. Cluster-specific polymerase chain reaction amplification of $16 \mathrm{~S}$ rDNA sequences for detection and identification of Mycoplasmalike Organisms. Phytopathology 83 (9): 1008-1011. https://doi.org/10.1094/Phyto-83-1008

DERY, K. S.; MARIAU, D.; PHILIPPE, R. 1996. Auchenorrhyncha (Homoptera), suspected vectors of coconut lethal yellowing disease in Ghana. Plantations, Recherche, Développement 3 (5): 355-363.

DICKINSON, M.; TUFFEN, M.; HODGETTS, J. 2013. The Phytoplasmas: An introduction. En: Dickinson, M.; Hodgetts, J. (Eds.). Phytoplasma. Methods in molecular biology (Methods and Protocols). Vol. 938. Humana Press, Totowa, NJ. 421 p. https://doi.org/10.1007/978-1-62703-089-2 1

DOLLET, M.; LLAUGER, R.; FABRE, S.; JULIA, J. F.; GONZALEZ, C.; CUETO, J. R. 2010. Nymphocixia caribbea (Fennah) (Homoptera: Cixiidae) potential candidate as coconut lethal yellowing vector in the Carribean. En: COST Action FA0807. Current status and perspectives of phytoplasma disease research and management, Sitges, Espagne, 1-02 February 2010. Disponible en: https://agritrop.cirad.fr/555468/ [Fecha revisión: 31 julio 2018].

DOLLET, M.; MACOME, F.; VAZ, A.; FABRE, S. 2011. Phytoplasmas identical to coconut lethal yellowing phytoplasmas from Zambesia (Mozambique) found in a pentatomide bug in Cabo Delgado province. Bulletin of Insectology 64 (Supplement): S139-S140. Disponible en: https://agritrop.cirad.fr/562170/ [Fecha revisión: 6 agosto 2018].

EDEN-GREEN, S. 1979. Attempts to transmit lethal yellowing disease of coconuts [Cocos nucifera L.] in Jamaica by leaf hoppers (Homoptera: Cicadelloidea). Tropical Agriculture (Trinidad y Tobago) 56 (3): 185-192.

EDWIN, B. T.; MOHANKUMAR, C. 2007. Molecular identificación of Proutista moesta as the vector and the phylogenetic analysis of KWD in India. Indian Journal of Biotechnology 6: 560-563. http://nopr.niscair.res.in/bitstream/123456789/3086/1/ IJBT\%206\%284\%29\%20560-563.pdf

GALETTO, L.; PEGORARO, M.; MARZACHI, C.; ROSSI, E.; LUCCHI, A.; BOSCO, D. 2019. Potential role of the alien planthopper Ricania speculum as vector of Flavescence dorée phytoplasma. European Journal of Plant Pathology 154 (4): 11031110. https://doi.org/10.1007/s10658-019-01731-0

HARRISON, N.; RICHARDSON, P.; TSAI, J. H.; EBBERT, M.; KRAMER, J. P. 1996. PCR assay for detection of the phytoplasma associated with maize bushy stunt disease. Plant Disease 80 (3): 263-269. https://doi.org/10.1094/PD-80-0263

HARRISON, N. A.; WOMACK, M.; CARPIO, M. L. 2002. Detection and characterization of a lethal yellowing (16SrIV) group phytoplasma in Canary Island date palms affected by lethal decline in Texas. Plant Disease 86 (6): 676-681. https://doi. org/10.1094/PDIS.2002.86.6.676

HARRISON, N.; HELMICK, E.; ELLIOTT, M. 2008. Lethal yellowing-type diseases of palms associated with phytoplasmas newly identified in Florida, USA. Annals of Applied Biology 153 (1): 85-94. https://doi.org/10.1111/j.1744-7348.2008.00240.x

HOGENHOUT, S. A.; OSHIMA, K.; AMMAR, E. D.; KAKIZAWA, S.; KINGDOM, H. N.; NAMBA, S. 2008. Phytoplasmas: bacteria that manipulate plants and insects. Molecular Plant Pathology 9 (4): 403-423. https://doi.org/10.1111/j.13643703.2008.00472.x

HOWARD, F. W. 1986. Myndus crudus (Homoptera: Cixiidae), a vector of lethal yellowing of palms. pp. 117-129. En: Wilson, M. R.; Nault, L. R. (Eds.). Proceedings of 2nd International Workshop on Leafhoppers and Planthoppers of Economic Importance. Brigham Young University, Provo, Utah, EE. UU.

HOWARD, F. W. 2001. Sap-feeders on palms. pp. 109- 232. En: Howard, F. W.; Moore, D.; Giblin-Davis, R. M.; Abad, R. G. (Eds.). Insects on palms. CABI Publishing. Wallingford, Reino Unido, 403 p. https://doi.org/10.1079/9780851993263.0109 
HOWARD, F. W.; NORRIS, R. C.; THOMAS, D. L. 1983. Evidence of transmission of palm lethal yellowing agent by a planthopper, Myndus crudus (Homoptera, Cixiidae). Tropical Agriculture 60 (3): 168-171.

JARAUSCH, W.; FUCHS, A.; JARAUSCH, B. 2010. Establishment of a quantitative real-time PCR assay for the specific quantification of ' $\mathrm{Ca}$. Phytoplasma prunorum' in plants and insects. Julius-Kühn-Archiv 427: 392-394. https://ojs.openagrar.de/index. php/JKA/article/view/623

KRAMER, J. P. 1977. Taxonomic study of the planthopper genus Oecleus in the United States (Homoptera: Fulgoroidea: Cixiidae). Transactions of the American Entomological Society 103 (2): 379-449. Disponible en: https://www.jstor.org/stable/25078207 [Fecha revisión: 6 agosto 2018].

KRAMER, J. P. 1979. Taxonomic study of the planthopper genus Myndus in the Americas (Homoptera: Fulgoroidea: Cixiidae). Transactions of the American Entomological Society 105 (3): 301-389. https://www.jstor.org/stable/25078242

KWADJO, K. E.; BEUGRÉ, N. D. I.; DIETRICH, C. H.; THIERRY KODJO, A. T.; ATTA DIALLO, H.; YANKEY, N.; DERY, S.; WILSON, M.; KONAN KONAN, J. N.; CONTALDO, N.; PALTRINIERI, S.; BERTACCINI, A.; AROCHA ROSETE, Y. 2018. Identification of Nedotepa curta Dmitriev as a potential vector of the Côte d'Ivoire lethal yellowing phytoplasma in coconut palms sole or in mixed infection with a 'Candidatus Phytoplasma asteris'-related strain. Crop Protection 110: 48-56. https://doi. org/10.1016/j.cropro.2017.12.015

LEE, I. M.; DAVIS, R. E.; GUNDERSEN-RINDAL, D. E. 2000. Phytoplasma: Phytopathogenic Mollicutes. Annual Reviews in Microbiology 54 (1): 221-255. https://doi.org/10.1146/annurev. micro.54.1.221

LIU, J.; GOPURENKO, D.; FLETCHER, M. J.; JOHNSON, A. C.; GURR, G. M. 2017. Phytoplasmas-The "Crouching Tiger" Threat of Australian Plant Pathology. Frontiers in Plant Science 26: 599. https://doi.org/10.3389/fpls.2017.00599

LU, H.; WILSON, B. A. L.; ASH, G. J.; WORUBA, S. B.; FLETCHER, M. J.; YOU, M.; YANG, G.; GURR, G. M. 2016. Determining putative vectors of the Bogia coconut syndrome phytoplasma using loop-mediated isothermal amplification of single-insect feeding media. Scientific Reports 6 (1): 35801. https://doi. org/10.1038/srep35801

MARTÍNEZ, R. T.; NARVÁEZ, M.; FABRE, S.; HARRISON, N.; OROPEZA, C.; DOLLET, M.; HICHEZ, E. 2008. Coconut lethal yellowing on the southern coast of the Dominican Republic is associated with a new $16 \mathrm{SrIV}$ group phytoplasma. Plant pathology 57 (2): 366-366. https://doi.org/10.1111/j.1365-3059.2007.01726.x

MPUNAMI, A.; TYMON, A.; JONES, P.; DICKINSON, M. J. 2001. Identification of potential vectors of the coconut lethal disease phytoplasma. Plant Pathology 49 (3): 355-361. https://doi. org/10.1046/j.1365-3059.2000.00460.x

MYRIE, W.; HARRISON, N.; DOLLET, M.; BEEN, B. 2007. Molecular detection and characterization of phytoplasmas associated with lethal yellowing disease of coconut palms in Jamaica. Bulletin of Insectology 60 (2): 159-160. http://www.bulletinofinsectology.org/pdfarticles/vol60-2007-159-160myrie.pdf

MYRIE, W.; OROPEZA, C.; SAENZ, L.; HARRISON, N.; ROCA, M. M.; CÓRDOVA, I.; KU, S.; DOUGLAS, L. 2011. Reliable improved molecular detection of coconut lethal yellowing phytoplasma and reduction of associated disease through field management strategies. Bulletin of Insectology 64: S203-S204. http://www.bulletinofinsectology.org/pdfarticles/vol64-2011S203-S204myrie.pdf

NARVÁEZ, M.; VÁZQUEZ-EUÁN, R.; HARRISON, N. A.; NIC-MATOS, G.; JULIA, J. F.; DZIDO, J. L.; FABRE, S.; DOLLET, M.; OROPEZA, C. 2018. Presence of 16SrIV phytoplasmas of subgroups A, D and E in planthopper Haplaxius crudus Van Duzee insects in Yucatán, Mexico. 3 Biotech 8: 61. https:// doi.org/10.1007/s13205-018-1094-5
POWELL, C. M.; HAIL, D.; POTOCNJAK, J.; HANSON, J. D.; HALBERT, S. H.; BEXTINE, B. R. 2015. Bacterial community composition of three candidate insect vectors of palm phytoplasma (Texas Phoenix Palm Decline and Lethal Yellowing). Current Microbiology 70: 240-245. https://doi.org/10.1007/s00284-014-0709-2

RASHIDI, M.; D'AMELIO, R.; GALETTO, L.; MARZACHİ, C.; BOSCO, D. 2014. Interactive transmission of two phytoplasmas by the vector insect. Annals of Applied Biology 165 (3): 404413. https://doi.org/10.1111/aab.12146

REINERT, J. A. 1977. Field biology and control of Haplaxius crudus on St. Augustinegrass and Christmas palm. Journal of Economic Entomology 70 (1): 54-56. https://doi.org/10.1093/jee/70.1.54

SFORZA, R.; BOURGOIN, T.; WILSON, S. W.; BOUDON-PADIEU, E. 1999. Field observations, laboratory rearing and descriptions of immatures of the planthopper Hyalesthes obsoletus (Hemiptera: Cixiidae). European Journal of Entomology 96 (4): 409-418. https://www.eje.cz/artkey/eje-199904-0015_ Field_observations_laboratory_rearing_and_descriptions_of_immatures_of the planthopper_Hyalesthes_obsoletus_H.php

SMART, C. D.; SCHNEIDER, B.; BLOMQUIST, C. L.; GUERRA, L. J.; HARRISON, N. A.; AHRENS, U.; LORENZ, K. H.; SEEMÜLLER, E.; KIRKPATRICK, B. C. 1996. Phytoplasma-specific PCR primers based on sequences of the 16S-23S rRNA spacer region. Applied and Environmental Microbiology 62 (8): 29882993. https://doi.org/10.1128/AEM.62.8.2988-2993.1996

THOMAS, D.; NORRIS, R. 1980. The use of electron microscopy for lethal yellowing diagnosis [Cocos nucifera]. Proceedings of the annual meeting of the Florida State Horticultural Society, EE. UU. 93: 196-199.

TSAI, J. H.; KIRSCH, O. H. 1978. Bionomics of Haplaxius crudus (Homoptera: Cixiidae). Environmental Entomology 7 (2): 305308. https://doi.org/10.1093/ee/7.2.305

TSAI, J. H.; WOODIEL, N. L.; KIRSCH, O. H. 1976. Rearing tecniques for Haplaxius crudus (Homoptera: Cixiidae). Florida Entomologist 59 (1): 41-43. https://doi.org/10.2307/3493167

TYMON, A. M.; JONES, P.; HARRISON, N. A. 1997. Detection and differentiation of African coconut phytoplasmas: RFLP analysis of PCR-amplified 16S rDNA and DNA hybridisation. Annals of Applied Biology 131 (1): 91-102. https://doi. org/10.1111/j.1744-7348.1997.tb05398.x

TYMON, A. M.; JONES, P.; HARRISON, N. A. 1998. Phylogenetic relationships of coconut phytoplasmas and the development of specific oligonucleotide PCR primers. Annals of Applied Biology 132 (3): 437-452. https://doi.org/10.1111/j.1744-7348.1998. tb05220.x

VÁZQUEZ-EUÁN, R. C. 2010. Detección y caracterización de fitoplasmas del grupo del amarillamiento letal en diferentes especies de palmeras en Yucatán. Tesis de Doctorado en Ciencias y Biotecnología de Plantas. Centro de Investigación Científica de Yucatán. Mérida, Yucatán, México. 75 p. Disponible en: http:// cicy.repositorioinstitucional.mx/jspui/handle/1003/596 [Fecha revisión: 6 agosto 2018].

VÁZQUEZ-EUÁN, R.; HARRISON, N.; NARVÁEZ, M.; OROPEZA, C. 2011. Occurrence of a 16SrIV group phytoplasma not previously associated with palm species in Yucatan, Mexico. Plant Disease 95 (3): 256-262. https://doi.org/10.1094/PDIS-0210-0150

WEINTRAUB, P. G. 2007. Insect vectors of phytoplasmas and their control-an update. Bulletin of Insectology 60 (2): 169-173. http://www.bulletinofinsectology.org/pdfarticles/vol60-2007169-173weintraub.pdf

WEINTRAUB, P. G.; BEANLAND, L. 2006. Insect vectors of phytoplasmas. Annual Review of Entomology 51: 91-111. https:// doi.org/10.1146/annurev.ento.51.110104.151039

WILSON, S. W. 2005. Keys to the families of Fulgoromorpha with emphasis on planthoppers of potential economic importance in the southeastern United States (Hemiptera: Auchenorrhyncha). Florida Entomologist 88 (4): 464-481. https://doi. org/10.1653/0015-4040(2005)88[464:KTTFOF]2.0.CO;2 


\section{Origen y financiación}

La presente investigación forma parte del trabajo de tesis de Doctorado en Ciencias del primer autor. La Unión Europea proporcionó fondos en el marco del proyecto Horizonte 2020: Enfermedades asociadas a procariotas transmitidas por insectos en cultivos perennes tropicales y subtropicales (TROPICSAFE: Acuerdo de subvención No. 727459).

\section{Contribución de los autores}

Eder Ramos-Hernández, Julia María Lesher-Gordillo, Carlos Fredy Ortiz-García, Carlos Oropeza-Salin: formularon originalmente la idea, muestreo de insectos, revisión de resultados y redacción del artículo.

Saúl Sánchez-Soto: responsable en la identificación y la confirmación de las especies de cíxidos y dérbidos de este artículo.

Miguel A. Magaña-Alejandro: revisión y sugerencias al artículo.

Maria Del S. Narváez-Cab: trabajo molecular en laboratorio, escritura del artículo. 